\title{
Lucro de ação: um exame das condições de possibilidade do magistério oficial
}

Gilson R. de M. Pereira

Maria da Conceição

Lima de Andrade

Palavras-chave: profissão

docente; carisma; dádiva;

condições de trabalho; lucro de ação.

\section{Resumo}

Realizado a partir de questionários e entrevistas com 36 professoras de escolas públicas de uma das regiões mais pobres do País, tem por objetivo lançar luz nas condições de existência e no espaço dos possíveis do magistério oficial. Dispondo de uma missão e firmadas como agentes ativos da produção simbólica, embora ocupantes dos postos mais inferiores das escalas de prestígio intelectual, as professoras pesquisadas depositam na adesão dóxica às coisas da escola todas as razões de ser do futuro pessoal. Essa adesão manifesta-se no carisma, ou seja, na atitude antieconômica de recusa ao cálculo estritamente econômico no governo da própria vida. Desse modo, o interesse pessoal e a libido profissional convergem para lucros não necessariamente econômicos, sugerindo um caso no qual as práticas e percepções, conquanto coagidas pela lógica do mercado, são comandadas pelo "atrativo da dádiva". Além disso, a investigação tornou possível a descrição da rotina de trabalho dessas professoras. Tudo o que, pelo menos nos grandes centros, se compreende como trabalho pedagógico ou rotina da profissão docente, parece sofrer uma transmutação nessas escolas e nesses exercícios profissionais. O estudo se justifica considerando que a análise das práticas, das posições ocupadas pelos membros do magistério e das tomadas de posição correspondentes permite compreender o lucro de ação característico dessa profissão.

\section{Introdução}

Como é possível o magistério oficial? O que leva alguém a ingressar e permanecer numa carreira de baixos retornos materiais e simbólicos? Como é possível suportar o desgosto e a insatisfação permanentes de uma atividade habituada, sob a forma dilacerada do sofrimento, da decepção, da expectativa e da esperança, às péssimas condições de trabalho, aos salários aviltantes e, sobretudo, ao descaso, ao esquecimento e ao não-reconhecimento ou ao reconhecimento apenas formal por parte dos poderes públicos e da sociedade? Que gratificações alguém obtém alocado nas posições mais humildes de uma carreira condenada à humildade? Para elucidar essas questões, tantas vezes abordadas na literatura educacional, certamenteé insuficiente recorrer à pura e simples coerção da vida econômica: vivendo sob a marca da privação, o professor da rede pública, no entanto, não é necessariamente o proletário cuja condição foi habilmente descrita por analistas do campo educacional (Pucci, Oliveira, Squissardi, 1991). Em razão dos reduzidos créditos obtidos ao longo de toda uma vida de trabalho, também não é pertinente atribuir ao membro do magistério oficial o desejo utilitário de "escalada social". Longe de ser um joguete das forças econômicas ou um calculista estratégico, o membro do magistério oficial (em geral, 
professoras normalistas, pedagogas ou cursando graduação em Pedagogia) persegue fins não necessariamente manifestos em suas intenções explícitas, ou seja, as recompensas materiais e simbólicas proporcionadas por uma profissão e seu respectivo exercício. Além disso, ele luta por algo que está além dessas recompensas, quer dizer, o lucro de ação presente "no fato de sair da indiferença e de se afirmar como agente ativo, preso ao jogo, ocupado, um habitante do mundo habitado pelo mundo, projetado para fins e dotado objetivamente, portanto, subjetivamente, de uma missão social" (Bourdieu, 1992, p. 49. Grifo nosso).

Este texto apresenta os resultados de uma pesquisa apoiada em questionários e entrevistas com 36 professoras de dez escolas públicas, urbanas e rurais, do município de Baraúna, na região oeste do Rio Grande do Norte, realizada durante o ano letivo de 2001. As professoras faziam parte de um universo de 45 profissionais pertencentes a uma mesma turma de um curso voltado à obtenção da habilitação de nível superior no magistério das séries iniciais. O uso do questionário justifica-se em razão da necessidade de se fazer um diagnóstico prévio das condições socioeconômicas das professoras (escolaridade dos pais, anos de profissão, vencimentos salariais, posição na carreira, entre outras). As entrevistas, por sua vez semi-estruturadas, objetivaram obter informações acerca dos pontos de vista das professoras sobre seu cotidiano, aspirações e dificuldades profissionais.

O objetivo da investigação é lançar luz nas condições de existência e no espaço dos possíveis de uma profissão reconhecidamente difícil de existir, especialmente numa das regiões mais pobres do País, e nisso reside o caráter exemplar do apetrecho empírico aqui manuseado. A análise das práticas, das posições ocupadas pelos membros do magistério e das tomadas de posição correspondentes auxilia na compreensão - "sem rir, nem deplorar", como recomendado por Spinoza - do lucro de ação específico oferecido por essa profissão aos que a ela dedicam seu tempo e seus esforços.

\section{O espaço social das professoras}

A análise das condições de exercício profissional do professorado público pressupõe a descrição das propriedades (os capitais) dos membros do magistério. A descrição das propriedades e dos espaços social e físico nos quais se inserem os agentes contribui para a compreensão das oportunidades médias de sucesso e fracasso e dos rendimentos tanto materiais como simbólicos associados a essa profissão.

As professoras entrevistadas eram todas, à época da pesquisa, formadas no Curso Normal e lecionavam nas séries iniciais do ensino fundamental. Trata-se, portanto, em razão dos reduzidos capitais simbólicos, de agentes ocupantes dos postos mais dominados do campo educacional. O tempo de exercício profissional variava de seis meses a 20 anos. Estas professoras estavam, mesmo suportando uma estafante jornada extra de trabalho, cursando o Proformação, aos sábados, na Universidade do Estado do Rio Grande do Norte (UERGN), para obter, conforme já mencionado, a habilitação de nível superior no magistério das séries iniciais. Embora o programa fosse resultado de convênio do governo federal com as prefeituras da região, essas professoras pagavam o referido curso, o que reduzia ainda mais seus vencimentos.

Funcionalmente admitidas para ganhar o salário mínimo, algumas das professoras, em razão dos custos com o curso (mensalidade, transporte e alimentação), estavam recebendo $\mathrm{R} \$ 15$ por mês. Conquanto ganhando pouco para os padrões urbanos, sobretudo os do sudeste e sul do País, essas professoras fazem parte, mesmo sem disso ter consciência, da "elite" do município: têm rendimentos razoavelmente fixos e não trabalham na lavoura, numa região de trabalho predominantemente manual e sazonal, quando não, incerto. Filhas de trabalhadores rurais e urbanos, analfabetos e semi-analfabetos (exceto uma, cujo pai havia completado o $2^{\circ}$ grau), conseguiram fugir, de algum modo, ao destino comum do trabalho manual, e isso constitui para elas enorme fonte de satisfação pessoal ("me sinto recompensada"; "a minha profissão é gratificante"). Por meio de investimentos materiais e, sobretudo, afetivos, tão mais duramente suportados ("muito lutei para chegar aonde cheguei") quanto maior as dúvidas e dificuldades enfrentadas, essas professoras conseguiram se situar num ponto do espaço social que, correlativo ao espaço físico onde atuam, permite o ganho de posição, isto é, essa forma propriamente não-capitalista de acumulação de capitais caracterizada pela 
posse de um capital distintivo (no caso, ser professora num município pobre). Isso pode ser exemplificado tanto no fato de as professoras solteiras, sobretudo aquelas em início de carreira, serem cortejadas pela população masculina (as professoras revelaram que os rapazes solteiros dos locais de suas escolas consideravam-nas "bons-partidos", mirando-as a partir de suas estratégias matrimoniais), como em todos os aparentemente minúsculos e imperceptíveis gestos de deferência destinados a elas pela população ("me sinto valorizada pelos pais dos meus alunos"; "aquele abraço espontâneo e o sorriso largo que vejo em seus rostos todas as manhãs"; "somos tratadas com muito carinho, respeito e admiração por parte dos moradores das comunidades, e isso nos gratifica e estimula a enfrentar os problemas cotidianos").

Mesmo nesse universo aparentemente homogêneo, nivelado pelos reduzidos créditos simbólicos, há hierarquias não imediatamente perceptíveis. $\mathrm{O}$ posto mais baixo e menos considerado, segundo a percepção e experiência dos agentes, é o de professora na educação infantil nas creches ("nós, do pré-escolar, somos excluídas pelos outros professores"):

\section{- Outro fator muito negativo [registra uma professora] é o nosso pagamento, pois, como trabalhamos com a educação infan- til, não temos direito aos recursos do Fundef, e nem tampouco às sobras que os outros professores recebem. Até mesmo o nosso pagamento é em dias diferentes dos professores do ensino fundamental.}

Trabalhando duro, fazendo, como elas disseram, "finca-pé" no magistério, poupando quando possível, dedicandose a alunos que, em suas palavras, "são carentes de tudo", suportando a burocracia e o esquecimento dos poderes públicos ("nossos governantes precisam olhar para o educador"), essas professoras parecem produzir estratégias voltadas a colimar esforços direcionados a manterem-se presas ao jogo, ao trabalho e ao ofício de ensinar, de "passar conhecimentos" numa região na qual tanto o trabalho é precário e intermitente quanto o conhecimento propriamente escolar é em si um bem raro e esotérico. Para elas, as gratificações profissionais não parecem, de algum modo, ser conseqüência nem dos vencimentos (de resto, irrisórios quando comparados com os de outros segmentos profissionais, mesmo da região; "estou pagando para trabalhar", disse uma professora cujo contracheque revelava um débito, que a mesma alegava desconhecer, com a prefeitura), nem necessariamente do agradecimento social (embora algumas professoras fizessem questão de sublinhar a atenção dos moradores, como referido anteriormente, outras registravam uma percepção diferente: "ninguém olha para nós"; "não somos prioridade"; "não somos reconhecidas pelo nosso trabalho"). A análise do apetrecho empírico, portanto, sugere que as práticas das professoras são orientadas pelo interesse no desinteresse, ou, melhor dizendo, suas práticas e percepções, conquanto coagidas pela lógica do mercado, são comandadas pelo "atrativo da dádiva". Como escreve Godbout (1998, p. 49):
A dádiva seria uma experiência de aban- dono à incondicionalidade, experiência de pertencer a uma comunidade que, longe de limitar a personalidade de cada uma, ao contrário, a expande. Contrariamente a uma visão individualista, a experiência de solidariedade comunitária não contradiz necessariamente a afirmação da identida- de e pode, ao contrário, desenvolvê-la. A dádiva seria, assim, uma experiência soci- al fundamental no sentido literal, de expe- riência dos fundamentos da sociedade, da- quilo que nos liga a ela para além das re- gras cristalizadas e institucionalizadas.

Saídas da indiferença civil, isto é, dispondo de um trabalho, de uma tarefa, de uma missão, ou, como elas registram, de um papel na comunidade ("estou sempre procurando aperfeiçoar-me para melhor desempenhar meu papel profissional e social"; "meu objetivo é ser uma boa profissional, trabalhando com bastante empenho e desempenhando o papel de educadora"), e firmadas como agentes ativos da produção simbólica, embora, como já mencionado, ocupantes dos postos mais inferiores das escalas de prestígio intelectual, essas professoras depositam na adesão dóxica às coisas da escola todas as razões de ser do futuro pessoal ("não mudaria de profissão"; "não tenho projetos fora da escola"; "gosto tanto do que faço que não deixaria de lecionar: é o meu mundo"). Essa adesão se manifesta no carisma profissional, no sentido, como será visto na frente, de atitude antieconômica, ou seja, recusa ao cálculo estritamente econômico no governo da própria vida. "O carisma", observa 
Weber (1994, p. 160), "é especificamente alheio à economia". Isso sugere que a incorporação do carisma como qualidade pessoal ou propriedade de uma função (carisma de cargo) conduz à substituição do aproveitamento econômico das ações por formas de ganhos cuja tipicidade revela a "renúncia às lutas econômicas". Nesse caso, o interesse pessoal e a libido profissional convergem para lucros não necessariamente econômicos, ou seja, para retornos expressos na própria ação: "meu maior desejo [confessa uma professora] é ser reconhecida profissionalmente, merecendo o devido valor e respeito"; "o que me importa é o sorriso e a aprendizagem de meus alunos". A saída carismática para as angústias e problemas profissionais parece adequada aos agentes compelidos a suportar tanto a dominação econômica (origem social humilde), como a simbólica (agentes ocupantes dos postos menos prestigiados da carreira) e de gênero (mulheres).

\section{Espaço físico: o município de Baraúna, $\mathbf{R N}$}

"A posição de um agente no espaço social", afirma Bourdieu (1993, p. 251-252), "se exprime no lugar do espaço físico em que está situado [...] e pela posição relativa que suas localizações temporárias e, sobretudo, permanentes ocupam em relação às localizações de outros agentes". Proprietárias de reduzidos capitais simbólicos, relativamente ao campo educacional, as professoras dessa região estão condenadas ao exercício profissional em um espaço físico cujas características são a distância e o vazio, portanto, espaço físico marginal e pouco valorizado. De fato, para sugerir as condições sociais de produção dos pontos de vista das professoras é talvez suficiente afirmar que o município de Baraúna, RN, é um dos mais pobres do País. Situado no semi-árido do Nordeste, assolado por verões prolongados e causticantes, com baixa densidade populacional (de acordo com dados fornecidos pelo IBGE, a densidade demográfica do município é de 19,34 habitantes por $\mathrm{km}^{2}$ ) e, excetuando a sede do município, em geral, ocupado por casarios dispersos (arruados, ranchos, sítios, "boqueirões"), e, além disso, movido por uma incipiente agricultura e praticamente sem atividade industrial, o município ocupa um inexpressivo lugar na escala nacional do índice de desenvolvimento humano (ocupa a 4.008 ${ }^{\mathrm{a}}$ posição no mapa da pobreza, cf. Pochmann, Amorim, 2003). As atividades econômicas são constituídas, basicamente, de um comércio precário e uma agricultura de subsistência, ressalvada a recém-iniciada cultura do melão. Os serviços públicos são quase inexistentes. Além disso, alimentando o ciclo vicioso da pobreza endêmica, a corrupção e o desmando administrativo compõem o pão cotidiano da vida política do município. Sintoma disso pode ser observado no afastamento, em 2004, do prefeito da cidade por irregularidades.

O município de Baraúna tem uma extensão territorial de $889 \mathrm{~km}^{2}$, o que equivale a 1,65\% da superfície estadual, e está situado, conforme dito, na região oeste do Estado do Rio Grande do Norte. As tabelas e os quadros anexos foram selecionados para elucidar o perfil humano e socioeconômico do município. É notável, como já mencionado, a ausência de atividade industrial, correlata a uma agricultura incipiente (Quadro 2). A instituição de ensino superior mais próxima é a Universidade do Estado do Rio Grande do Norte (UERN), localizada em Mossoró, cidade a 46 km de Baraúna. Nessa instituição, vale lembrar, as professoras pesquisadas estavam cursando, na época, o Proformação.

\section{Ausências e urgências}

O exercício do magistério, nessa região, é particularmente sujeito a dificuldades. Percebidas como "insatisfatórias", quando não como "péssimas", as condições de trabalho das professoras as condenam à gestão das urgências. A generalizada falta de recursos e infra-estrutura - "a escassez de material é muito grande"; "má conservação da instituição escolar"; "as salas são apertadas, há falta de material didático e não há área de lazer"; "o prédio é oferecido pela comunidade, mas não dispomos de energia, banheiro e outras coisas mais"; "a maioria das escolas da zona rural é precária, não tem sequer o necessário. O que existe é só a boa vontade, a inteligência e o interesse do professor" - parece configurar, ainda hoje, um cenário no qual a educação escolar não encontra sustentação na gestão pública e tampouco integra as estratégias das famílias dos trabalhadores rurais locais. Exemplo 
disso é o fato de uma professora ter se referido ao constante roubo da merenda escolar pelas próprias famílias dos alunos. Pressionadas pela necessidade, e sem ter exata noção do mal que faziam aos próprios filhos, e, ao mesmo tempo, identificando a merenda como mercadoria do governo, portanto, propriedade de um agente estranho, e até hostil, as famílias não hesitavam em roubá-la. Referindo-se às condições de insegurança vigentes no exercício profissional em escolas isoladas naquela região, onde não é incomum o trânsito de "puxadores-de-carros" conduzindo o produto do roubo para venda e desmanche no Ceará ("enfrento perigos, trabalho só, e a escola onde leciono não tem segurança"), uma professora mencionou - não sem rir - o modo pelo qual a então reduzida biblioteca da escola foi inteiramente perdida: um rebanho de bodes, uma das únicas formas de criação animal da região, invadiu a escola e comeu os livros.

Os efeitos de lugar são as formas pelas quais as características do espaço físico são incorporadas pelos agentes e, simultaneamente, os modos pelos quais os indivíduos emprestam ao espaço físico suas propriedades distintivas. "Se o habitat contribui para fazer o habitus", observa Bourdieu (1993, p. 259), "o habitus contribui também para fazer o habitat através dos costumes sociais mais ou menos adequados que ele estimula a fazer". Uma professora referiu-se à sua escola como "à beira do deserto". O deserto comparece na representação da professora como metáfora não só do desamparo social, senão também da solidão profissional (outra professora registrou: "trabalho sozinha, não tenho com quem discutir e tirar dúvidas"). Nenhuma delas mencionou quaisquer iniciativas municipal, estadual ou federal de apoio à carreira. Para além da súbita pressão decorrente da política do governo federal de graduar em prazo fixo todas as profissionais, com atuação em sala, com Curso Normal, as professoras estavam cursando o Proformação muito mais por iniciativa pessoal, com custo individual, do que como resultado de projetos públicos de qualificação profissional do professorado. Solitárias e profissionalmente desamparadas, as professoras incorporam o deserto e este, por um efeito de duplicação exponencial, estimula nelas os costumes sociais compatíveis (reclusão prolongada, silêncios, economia de gestos, etc.).
A pesquisa torna possível a descrição da dura e solitária rotina de trabalho dessas professoras. Levantar às $4 \mathrm{~h}$. É preciso deixar em casa tudo pronto para o dia, pois maridos e filhos também exigem cuidados. Pega-se um transporte coletivo improvisado (para o deslocamento das professoras, o termo "improvisado", via de regra, é eufemismo: os veículos são verdadeiras sucatas que, em razão da falta de fiscalização, ainda trafegam e põem vidas em risco todos os dias. Contudo, os proprietários dessas sucatas são beneméritos, pois sem isso o trajeto seria mesmo ou a pé ou no lombo de burro). O percurso é demorado, feito por descampados, sítios e lugarejos, em estradas de terra, poeirentas na estiagem ("meus cabelos vivem duros de poeira", disse uma professora) e lamaçais na época de chuvas ("uma ocasião, eu, toda pronta e arrumada para dar aula, me atolei até os joelhos na lama", disse outra).

\section{- O que me preocupa profissionalmente [disse uma professora] é a distância entre a escola e o professor. Alguns moram até 50 $\mathrm{km}$ da escola. Temos que enfrentar as terrí- veis estradas de barro, poeira, transportes malconservados, até o chamado "pau-de- arara", pago pelos próprios professores.}

Chega-se à escola e tem-se que fazer tudo, pois, em geral, as professoras estão sozinhas ou, quando muito, acompanhadas por alguém do lugar. Na seca, falta água. Quando há água ela é, normalmente, salobra, pois tirada de um poço. Boa para irrigar a lavoura do melão, a água salobra arrasa a saúde das professoras ("aqui a gente vive de licença médica"). Uma professora mencionou o fato de ter de levar um garrafão de 5 litros de água de casa para a escola e tomá-la quente, pois não há eletricidade e, mesmo se houvesse, não há geladeira. Os alunos esperam a chegada da professora: têm de 5 a 25 anos de idade. Freqüentam as aulas todos juntos na sala de ensino multisseriado. No intervalo do almoço, a comida é feita pela própria professora. Enfim, tudo o que, pelo menos nos grandes centros, se compreende como trabalho pedagógico parece faltar ou sofre uma transmutação que torna irreconhecível a rotina da profissão docente nessas escolas e nesses exercícios profissionais. A administração dessas urgências cotidianas é correlativa à ausência dos "mínimos institucionais" de sustentação da profissão, 
como, por exemplo, a ausência de plano de cargos e salários. Final do dia, volta para casa pelo mesmo percurso, enfrentando a mesma poeira ou a mesma lama. Em casa, a aguardam as tarefas domésticas, as preocupações com a família.

\section{Carisma e razão de existir}

Coagidas, como referido, por urgências, as professoras encontram, no carisma da profissão, a fonte e a razão de existir. Pelo menos no espaço social e físico aqui analisado, tudo indica que o carisma é uma propriedade simbólica central do magistério. Nestas notas, o conceito é utilizado não só no sentido de atitude tipicamente antieconômica, já mencionado, mas também no de vocação. "O carisma puro", define Weber (1994, p. 160), "constitui, onde existe, uma 'vocação', no sentido enfático da palavra: como 'missão' ou 'tarefa' íntima".

Como qualidade extracotidiana, o carisma é propriedade dos agentes situados nos postos mais altos dos campos simbólicos (autores, grandes acadêmicos, escritores de renome, entre outros), e como missão, vocação, é propriedade dos agentes alocados nos postos mais baixos das escalas intelectuais (professoras das séries iniciais, alfabetizadoras de adultos, entre outros exemplos). Também, segundo Weber, é uma atitude antieconômica, não porque o agente carismático recuse retornos materiais, mas porque recusa toda atitude econômica racional, a perseguição exclusiva de fins estritamente econômicos ("trabalho por amor aos meus alunos", disse uma professora).

O carisma é o centro de toda uma lógica da prática simbólica. Constitui uma espécie de operador prático que transforma os déficits (de posição, de localização, etc.) em rendimentos simbólicos pessoais. O agente carismático sente compensações íntimas mesmo nas tarefas socialmente mais desprezadas. O carisma supre o agente de imaginação autojustificadora; esta pode ser interpretada tanto como fonte de sentido quanto de eufemismo. É fonte de sentido, pois é da vocação que o agente do magistério extrai a sua libido profissional. Também opera como eufemização das mazelas crônicas de uma profissão dominada, situada nos níveis mais baixos das hierarquias simbólicas. Ao suportar o dia-a-dia de uma profissão que promete muito e cumpre tão pouco, o agente do magistério, ocupante dos postos mais humildes nas hierarquias funcionais, encontra no carisma um "fundamento cotidiano duradouro".

\section{Considerações complementares}

Para compreender o lucro de ação do magistério nessa área geográfica e social, é preciso balizar o espaço dos possíveis: situadas, como mencionado, em postos ínfimos das hierarquias simbólicas, as professoras localizam-se, no entanto, em lugares relativamente prestigiados ("me sinto valorizada, pois trabalho numa zona rural onde a maior parte das pessoas não sabe ler; com isso, nós, professores, somos considerados pessoas de muita importância e valor") e até cobiçados na região (há poucos postos de emprego). Além disso, condenadas a reduzidos rendimentos materiais, gozam de relativa, conquanto precária, estabilidade funcional e de privilégios decorrentes dos rendimentos fixos, mesmo baixos. Sofrem a indiferença dos poderes públicos (às vezes, a ação dos infinitos mecanismos disponíveis pelas hierarquias do serviço público para azucrinar a vida dos subalternos), porém usufruem a estima dos alunos e, não raro, dos pais. Coagidas pela lógica do mercado, as professoras são, em suas práticas e percepções, atraídas pela "lógica da dádiva". Todo seu ethos profissional é conformado por essa situação ambígua, cuja culminância parece ser a "heroicização da vida cotidiana", isto é, as professoras "transformam a vida numa corrida de obstáculos sem fim" (Wacquant, 1998, p. 92).

Finalmente, talvez seja o caso de observar que os excluídos do interior do sistema educacional compõem o conjunto dos que descobrem não ser suficiente ter acesso aos diversos graus de ensino para ter acesso às posições sociais mais vantajosas (Bourdieu, Champagne, 1993). De certa forma, as professoras localizadas nos postos mais ínfimos da carreira são os excluídos do interior do universo da produção simbólica. Fervorosas adeptas da democratização do ensino, são as primeiras vítimas desta, com a perda do valor distintivo de suas credenciais. Mas, se nos outros o sentimento de estar no sistema, sem gozar de seus lucros, é de frustração, essas professoras, por sua imensa adesão 
ao mundo da escola e, em razão do lucro de ação específico da profissão, mantêm sempre a esperança de retorno dos investimentos, em geral, penosamente realizados.

\section{Referências bibliográficas}

BOURDIEU, Pierre. Effets de lieu. In: BOURDIEU, Pierre (Org.). La misère du monde. Paris: Seuil, 1993. p. 249-262.

. Leçon sur la leçon. Paris: Minuit, 1992.

BOURDIEU, Pierre; CHAMPAGNE, Patrick. Les exclus de l'intérieur. In: BOURDIEU, Pierre (Org.). La misère du monde. Paris, Seuil, 1993. p. 913-923.

GODBOUT, Jacques T. Introdução à dádiva. Revista Brasileira de Ciências Sociais. São Paulo, v. 13, n. 38, p. 39-51, out. 1998.

POCHMANN, Márcio; AMORIM, Ricardo (Org.). Atlas da exclusão social no Brasil. São Paulo: Cortez, 2003.

PUCCI, Bruno; OLIVEIRA, Nelson R.; SQUISSARDI, Valdemar. O processo de proletarização dos trabalhadores em educação. Teoria \& Educação, n. 4, p. 91-108, 1991.

WACQUANT, Löic. Os três corpos do lutador profissional. In: LINS, D. (Org.). A dominação masculina revisitada. Campinas, SP: Papirus, 1998. p. 73-96.

WEBER, Max. Economia e sociedade. Fundamentos da sociologia compreensiva. 3. ed. Brasília, DF: EdUnB, 1994.

Gilson R. de M. Pereira, doutor em Educação pela Faculdade de Educação da Universidade de São Paulo (Feusp), é professor do Programa de Pós-Graduação em Educação da Fundação Universidade Regional de Blumenau (Furb).

gilsonmp@furb.br

Maria da Conceição Lima de Andrade, doutora em Ciências Sociais pela Pontifícia Universidade Católica de São Paulo (PUC-SP), é professora do Programa de Pós-Graduação em Educação da Fundação Universidade Regional de Blumenau (Furb).

mconceicao@furb.br

\section{Abstract}

Profit of action: an assessment of official teaching schools

This study has been carried out using questionnaires and interviews with 36 teachers of public schools in one of the poorest regions of the country and its aim is to shed light both over the conditions in these public schools occupy. Having a mission statement and performing it as active agents of the symbolic production, though situated in the lowest ranks of intellectual prestige, the teachers of this research consider the school matters as the reason of their personal future. This philosophy of life is expressed in their charisma, or 
so to say, in their anti-economical attitude, refusing a strictly economic evaluation while running their own life. Consequently, their personal interests and professional libido are drawn to non-necessarily economic profits, suggesting a case in which practices and perceptions, while coaxed by the market logic, are commanded by the attraction of the gift. Furthermore, the research made the description of the work routine of these teachers possible. Everything, at least in major centers, understood as pedagogic work or the routine of the teaching profession, seems to undergo a complete change in said schools and professional practices. The study is justified, considering that the analysis of the practices, of the positions occupied by teachers and of the related stands assumed, enables us to understand the profit of the action characteristic of the mentioned profession.

Keywords: teaching; charisma; gift; working conditions; profit of action.

Recebido em 16 de junho de 2005.

Aprovado em 23 de fevereiro de 2006. 


\section{Anexo}

Tabela 1 - Distribuição por sexo - Baraúna, RN - 2001

\begin{tabular}{|l|c|c|}
\multirow{2}{*}{ Sexo } & \multicolumn{2}{|c|}{ População } \\
\cline { 2 - 3 } & No de habitantes & \% de habitantes \\
\hline Masculino & 8.861 & 51,53 \\
\hline Feminino & 8.334 & 48,47 \\
\hline Total & $\mathbf{1 7 . 1 9 5}$ & $\mathbf{1 0 0 , 0 0}$ \\
\hline
\end{tabular}

Fonte: IBGE.

Tabela 2 - Distribuição por zona habitacional - Baraúna, RN - 2001

\begin{tabular}{|l|c|c|}
\multirow{2}{*}{ Zona } & \multicolumn{2}{|c|}{ População } \\
\cline { 2 - 3 } & No de habitantes & \% de habitantes \\
\hline Rurbana & 10.173 & 59,16 \\
\hline Total & 7.022 & 40,84 \\
\hline
\end{tabular}

Fonte: IBGE.

Tabela 3 - Distribuição por grupo de idade e razão de dependência* - Baraúna, RN - 2001

\begin{tabular}{|c|c|}
\hline Grupo de idade & $\mathbf{N}^{\circ}$ de habitantes \\
\hline 0 a 14 anos & 6.519 \\
\hline 15 a 64 anos & 9.769 \\
\hline $65+$ & 872 \\
\hline Razão de dependência** & 75,6577 \\
\hline
\end{tabular}

Quadro 1 - Dados e Informações complementares - Baraúna, RN - 2001

\begin{tabular}{|c|c|}
\hline Especificação & Numerário \\
\hline Entidades de ensino pré-escolar & 5 \\
\hline Entidades de ensino fundamental & 36 \\
\hline Entidades de ensino médio & 1 \\
\hline Entidades de ensino superior & 0 \\
\hline Hospitais & 1 \\
\hline Agências bancárias & 1 \\
\hline Domicílios & 3.816 \\
\hline Leitos (por mil habitantes) & 1,0468 \\
\hline Veículos registrados & 411 \\
\hline Ranking Geral no Estado - Baraúna (posição/média/índice final) & $\mathbf{7 4}$ \\
\hline
\end{tabular}

Fonte: Idec/RN. 
Quadro 2 - Dados e Informações complementares - Baraúna, RN - 2001

\begin{tabular}{|c|c|}
\hline Especificação & Numerário \\
\hline Freqüência à escola & $77,6273 \%$ \\
\hline Produção animal (em mil reais) & 817 \\
\hline Produção vegetal (em mil reais) & 4.000 \\
\hline
\end{tabular}

Fonte: Idec/RN. 